\title{
Analysis of the Artistic Technique and Performance Skills of Debussy's "Reflets Dans I'Eau"
}

\author{
Huan-Hao ZHANG \\ No.108 of Changanzhong Road Yanta District Xi'an Shaanxi province \\ Piano Department Of Xi'an Conservatory of Music \\ piano_hao@163.com
}

Keywords: Debussy; artistic technique; performance skills

\begin{abstract}
This paper analyzes the artistic technique and performance skills of Debussy's piano music by the literature method. The results show that this piece of music has distinct characteristics by it's of harmonic, texture and tonality distribution.
\end{abstract}

\section{Introduction}

Achille-Claude Debussy, the first composer completely breaking away from the traditional bondage of the first half of 20th century in France, is the impressionist originator, known as "the father of impressionism." His main works focus on piano and orchestral music. Through which series of theseexcellent works, he gradually established the basic characteristics of impressionism. Debussy applied the French Impressionist art to music, forming his own unique musical language. His work emphasizes the hazy impression of the musical style, and his creative themes are mainly around the natural scenery, the description of phenomenon and the performance of the custom of life, and his creative style is much focused on the harmonic of color changes [1]. "Images" separated from the traditional Western creation of the characteristics and formed its own unique musical style. Its distinctive impressionism making itself representative works [2]. One of the most well-known work is the first piece"Reflets dans l'eau" ("Reflections in the Water") [3], depicting the light and shadow staggered on the lake, and the sun scatter to forming little stars. While performing, more detailsis found from composer's keen capture of changes in the wind and water, delicate and vivid. His work has a transcendental significance, and with in-depth meaning of more studying.

\section{Performance skills of Debussy's Refletsdansl'eau}

This work is regarded as a trilogy with a rotation character: a similar series of clips repeated in the song, which can deepen the space of imagination. According to the subject motive and tonality distribution of the work as the basis for dividing the structure, the whole song is divided into "A-B-A1-B1-A2-Coda".

\section{Features of Part A}

Part A is from the 1st to the 23rd bar.1st and 2nd bar are in the left handpart of D-flat major and the right hand part is of the theme motive [4]. While playing, the chordpart of the right handneed to be very uniform, with the core near to five fingers to highlight the highest melody sound. While playing the chord, attention should be lay on conversion, to be prepared in advance. The bassopart consist of slow and deep touch, and cannot hear the sound head. The sound is similar to the even sound of "oin", and the intensity is played in pp. Because of the differences between different pianos, a proper weak pedal can be choose in the first place. And the sound effect cannot be too dark. In the 3rd and 4th bar, the left and right hand part of the tone is D-flat major. The 5th-8th bar is full of changes, with the disintegration of 1 st bar. It uses jitter pedal to achieve harmony and clean. The 9thand 10th use the original motive to shift the 16-minute note for the columnar chord chroma [5]. The 11thbar need growing intensity. When playing deep key, the arm strength sink, and highlight the high part of the melody. There is an approximate pause in 15th bar. The 16th bar is of high and low parts of the continuous sixteenth note parallel chord reverse. 17th and 18th bar 
appeared a very dramatic effect of the rhythm, playing with fast running fingers, moving wrist with the direction as a force transfer, then the natural formation of gradually strong and weak sound is formed. The 20th bar echo with soprano, with speed marked with a gradual sign. The 21 st bar is a repetition of the high octave of the previous bar. The 22nd and 23rd bar's harmony function and tone are not very clear. While playing, the fingers raised high, wrist to relax, touch with the pulp finger, slow down the key, the use of wrist for power transfer, and highlight the left hand whispering.

\section{Features of Part B}

This part includes 24th -35 thbars. From 24th to 29th bar, the music comes into the D major subordinate direction down on $\mathrm{G}$ major, at this time the high and low sound range widened, highlighting the continued characteristics of Debussy's tone. The 25th-28th bar use a multi-tone contrast approach, so that harmony shows a distinct feature, to further strengthen the high and low parts of the contrast. The 31 st and 32 nd bar is sixty-fourth note continuous tone down parallel plus three-chord. The 33rd and 35this repeated for the changes of the first two bars, and the extension of the triple-tone time at which the C-D is reduced. While playing, the arm and wrist should be relaxed, move with the notes. When playing the tercet, there is a strong sense of weakness, with harmony to play neat, and sound's superficies and intensity should have superimposed effect.

\section{Features of Part A1}

This part includes 36th-50th bar, which are the reproduction of part A, but the sound effect appears to be more dynamic. After the 8th bar of the subject motive, the 44th bar is the division of the original motive of the formation of the polygonal column chords comparing with Part A. The 48threflects the ability to control the fingertips, and the right hand'sdisintegration of the chord is the form of tercet; three tonein a group, but the bit is the first sound in the previous position, the formation of the first four tones, after two tones on three positions. Pay special attention to the use of the label of the law to play, between the tone and tone to be uniform, there cannot be accented [6]. While in the 49th-50th bar: the right hand play at the corner of the position; try to paste the key; each tone for a pedal, breath at one stretch; tone elongated constantly; the intensity grow gradually; the music is to a small climax.

\section{Features of Part B1}

This part is from 51st to 69th bar, which is the reproduction of the second subject, and 51st-59thare moved from the basso of part B to the soprano. The basso continue of the connection part of the material: describing the calm water and pure sound breaking the traditional harmony function, using different structural chords of the opposite, and disorder tone. It shows the water to speed up the play when with the touch play to ensure that the sound become soft and long. In 60th bar, after the transition of E-flat major, the intensity have been strengthened from the 58thffto 63rd bar until the tune to the climax, then slowly weakened. The second theme reappears in66th-70th bar expanding at the end of the subject, preparing for the return of major changes of D-flat major through constantly changes in tones, and at the same marital appearing in both Part A and Part B. The transition of the weave is like a change in the water.

\section{Features of Part A2}

This part is from the 71st to the $81 \mathrm{st}$ bar. The 70th bar is a smooth return to D-flat major. The first theme appears in the form of octave for the third time, with the right hand into the eighth note of tercet; in the value of the time on the expansion. The lines elongated, and it is more liberal. The 80th and 81st bar gradually fade, using of B1's the second theme rhythm of development process. The sound and rhythm are ease down, and the smooth access to the end of the whole music.

\section{Features of Coda}

This part is from 82ndto 95thbar, still follow the subject motive material. In the 86th bar, the use of a series of arpeggios shows water droplets fall after the aftermath of the spread. Finally, the left and 
right hand's range widened, with the beginning of the music interval echoes to the end of the entire music. While playing, the right hand keep the tone at the beginning of the theme. The sound should be clear, mixed effects, and slightly echoed highlighting the surrounding environment of the silence and water as the mirror of the sky. At this time: the wrist is to relax; cannot touch the key in the end; touch the key and flexible; and remind unlimited reverie.

\section{Discussion}

From the analyses above, we can clearly understand the composer's skills dealing the rhythm and chord. The status of chord has been highlighted and it break the chord's integrity, clearness, beautiful aesthetic. It can clearly found that the composer's care and thought on chord, his use of self-contained harmony, absorbing traditional music nutrients with bold innovation, maintain their own personality at the same time. As for the tone, it break single size layout of adjustment systemtoward diversification and stereoscopic direction [7]. Through the analyses of this music, more guidance and reference can be found for Impressionist music and even after the 20th century to our work today.

\section{References}

[1] Paul Landormy. Western music history [M]. Beijing: People's Music Publishing House, 1989.

[2] Zhang Hongdao. The History of European music [M]. Beijing: People's Music Publishing House, 1983.

[3] Thompson(translaters:ZhuXiaorong, Zhang Hongmo.) One man: Debussy and one artist [M]. Beijing: Central Conservatory of Music Press, 2006.

[4] Sang Tong. The history of the semitranslation [M]. Shanghai Music Publishing House, 2004.

[5] Wan Shuang. Creative featuresof Debussy 's "Reflections in the Water" [J]. Yellow River's Voice. 2013,6 (5): 31-33.

[6] Zhao Xiaosheng. Piano play the Road [M]. Shanghai: World Book Publishing Company, 1999.

[7] Frank Dawes. Debussy's Piano Music [M]. Beijing: People's Music Publishing House, 1985. 